\title{
Research on Translation Workshop Teaching
}

\author{
Junming Xiao \\ Qiqihar Medical University, Qiqihar Heilongjiang Province, 161006, China
}

Keywords: Translation workshop; Translation ability; English teaching

\begin{abstract}
Combined with practical experience in translation teaching, this paper firstly explains the definition, understanding, inspiration and characteristics of translation workshops, and puts forward the concrete steps of the translation workshop teaching method. At last, we conducted empirical research on the application effects of translation workshops in English teaching.
\end{abstract}

\section{Connotation of Translation Workshop}

In the early 1960s, translation is classified as a subject in the United States university system. Paul Engle started translation workshop in Iowa University, and grand literary translation for credits. From then on, literary translation occupy a important place in the history of American culture.

\subsection{Definition}

Gentzler defined the translation workshop as "similar to the translation center forum, there are two or more translators engaged in translation activities in the forum." (Gentzler, 1993) In fact, the definition of translation work is where a group of guys with same interests and hobbies gather together, study and discuss text translations, communicate with each other to share knowledge and experience, to solve the existing problems finally. Therefore, the translation workshop is not the same as the traditional translation course through instilling knowledge to students, but let them feel free to read, explain, and communicate with each other. It breaks traditional course in some form, and create freedom in certain extent. Translation workshop are the entities similar to language course and seminars, the translator is also a rapporteur (Brian Mossap, 1983). Also the translators is bound by the loyalty of the original work. In addition, translators use their own language organization ability to create. Translation workshop apply to a variety of text types of seminar.

\subsection{Understanding}

The translation workshop is like a mock forum with the significance of a serious formal meeting, organizations and participants act as different roles, such as translator custodian, translator. The role is assigned to develop the practice experience and skills, it is benefit for translators to learn in practical work experience, go through the problems occur on site, and develop their ability to solve problems quickly. In practical translation, the mental state and psychology, coordinate skills is an unavoidable problem that should be solved at first. The model of the simulation forum is a hypothesis site, a translator have a problem, will get a timely guidance and help from a small team, and each forum with different themes will be like this. This teaching model can help people learn how to solve problems quickly, and Strengthen confidence, finally grow into a translator who can adapt to all needs of the social society.

The translation workshop is like a institute of conference, roles are acts by students, the supervisor is the director of the Forum, whose main job is planning the conference theme, arrange and put forward the schedule of the meeting, including cooperative principle, evaluation criteria, the purpose of discussion, etc. The role of a supervisor is to discuss the version of the translated version by the leading members, help translator to complete the final version and finally publish it. Students is translators, who participate in the completion of the work, and make reasonable translation suggestions. 
Inspiration. Rhe existing problem is the teaching mode that has been used for many years in the classroom remains the same, the dilemma has not changed, and people have been seeking new teaching models that suitable for the development of today's society. The members of the translation workshop are participants and facilitators, students are participants, and teachers are facilitators. This process is centered on the student and the process of translation as a guidance. The teacher is the coordinator, the organizer, the supervisor, and the guide. Teachers should encourage students to engage in active communication, cooperation and interaction, expand their professional knowledge, and use certain translation techniques to solve the problems in translation. In the translation workshop, students can learn translation in the "translation", "learn translation in cooperation", and "learn the way of translation in the discussion."(LiMing, 2010) Improve the ability of translation and grasp the skills of translation through communication, communication and comprehension in the classroom to lay a good foundation for future translation activities.

In the teaching mode of translation workshop, students are the main part of learning and participate in the whole process of interaction. This helps to stimulate students' interest and encourage students' critical thinking. The process of mutual assistance helps students to eliminate tension and anxiety in their study and improve their learning efficiency. As a coordinator and facilitator in interaction, teachers can help students build up translation ability, so that students can not only acquire basic theoretical knowledge and specific translation skills, but also cultivate independent working ability and translation ability.

\subsection{Characteristics}

The translation workshop is centered on the translator (student), focus on practice, practice with translation theory and skill. Its main features are the selection of practical materials, put the translation skills into the basic knowledge, learn solve problem from practical experience. In the whole process of practice, there are self - study, multi - person and group cooperation, guidance of teachers, and communication between students. The evaluation of students' learning effect is based on the comprehensive examination form of classroom reporting, translation and final examination.

According to the characteristics and enlightenment of the translation workshop, a new teaching model can be applied in the translation class--translation workshop teaching model, which is organized the whole class, engage in the translation activities in groups, and through the examination or questionnaire or other tracking research, the best way for translation teaching is to engage in face-to-face discussions in the form of workshops and to combine with the networked interactive teaching model.

\section{Implementation Steps for Translation Workshop}

The application process of the translation workshop in the translation teaching class is based on a lot of academic research and the consideration of the characteristics of translation teaching in colleges and universities. The implementation steps for translation workshop is as Table 1.

Table 1. Implementation steps for translation workshop

\begin{tabular}{|c|c|l|}
\hline Stage & \multicolumn{1}{|c|}{ Step } & \multicolumn{1}{c|}{ Contents } \\
\hline Stage I (before translation) & Preparation & $\begin{array}{l}\text { Material collection, translation task } \\
\text { design }\end{array}$ \\
\hline Stage II (in translation) & Management & $\begin{array}{l}\text { Time control, independent translation } \\
\text { and group activities }\end{array}$ \\
\hline Stage III (after translation) & Evaluation & $\begin{array}{l}\text { Group evaluation, excellent work } \\
\text { show }\end{array}$ \\
\hline
\end{tabular}

Each of the above stages actually includes correspondingly different specific tasks, which need tutors and students to work hard together. Based on the characteristics of translation workshops and college English translation education, this paper designs a specific classroom teaching steps and procedures, divided into three stages: preparation phase, management phase and summary evaluation 
phase. In the workshop teaching mode, teachers are no longer leaders in learning activities, but students' hands-on ability and cooperative exploration ability are more valued and encouraged. In summary, the true focus of the workshop teaching model is on students' creative thinking and skills.

\subsection{Class preparation stage}

As we all know, perfect and meticulous classroom preparation is essential to the success of translation teaching. In translation workshop, Tutors need to gather a lot of relevant material, and design each concrete step to familiarize the students with the translation, as well as relevant translation strategies and techniques.

This stage mainly includes teacher's explanation and student's knowledge preparation. In the first section, the teacher spends about 20 minutes explaining basic knowledge of translation or basic questions about translation, highlight key points and difficulties. For instance, while explaining the theory of translation, the emphasis should be placed on the principles or standards of translation, translation skills and the basic knowledge of stylistic translation, and it is the most important thing to train the students' translation skills. The interpretation of common translation techniques should be clear and concise, focusing on the main points.

a) Design of translation materials and tasks: the collection of translation materials should be closely related to the students' specialties. In addition, the instructor should not only ensure that the translation task in the classroom is based on the materials collected, but also consider the skills used by students to deal with these materials.

b) Analysis and display of translation paradigms: after the completion of the design of translation materials and tasks, tutors can begin the lesson by teaching some essays and related translations. In addition, it is also necessary to analyze the accuracy and appropriateness of the translation of the model essay.

c) Study of translation theories and techniques: in class, before the translation task is fully discussed by the group, the instructor should display some basic translation skills, theory and process in different material forms. Only by such form, could students effectively use these translation theories, techniques and steps to accomplish different translation tasks, and then improve their level of translation.

d) Learning of translation steps: in the classroom of translation teaching, in addition to translation techniques and principles of translation, the instructor should help students learn the correct steps of translation.

\subsection{Class management stage}

In the translation workshop, the center of the classroom teaching is the students. The instructor divides the students into groups, and allow them to perform different translation tasks, aiming to further improve their translation ability. The instructor plays a very important role in the process of managing and controlling the whole class translation. After the preparation stage, students should begin to perform translation activities, and at this time, the instructor should try to ensure the harmonious and active atmosphere in the translation class.

a) Control of time and management of the group: on the one hand, the instructor should design how to control the time in the classroom, on the other hand, he also has to consider how to effectively manage translation groups. Managers should make full use of their time, with full consideration to all possible factors. The instructor needs to divide the time of a class into different parts, so that different tasks can be completed successively.

b) Group inquiry and personal translation practice: When the teacher confirms that all the students have understood their translation tasks, he should organize students to communicate in groups and explore how to accomplish their translation tasks, which is so called group inquiry. After the students have a deep understanding of the original text, they need to consider how to translate the original text carefully through their own different translation skills and principles.

c) Group mutual correction and cooperative learning: as the students gradually completed their personal translation work, they can start to do some mutual correction work between groups. Each 
members of group can compare their translations with others, so that better master the translation methods and techniques of translating the source language into the target language.

\subsection{Evaluation stage}

The evaluation work is very necessary in the translation workshop, because it enables students to realize how to deal with phase type materials.

a) Group evaluation: the members of a translation team must cooperate with each other to complete the translation task. However, the translation task completed by a group is not an independent and complete work, and it still needs other groups to further proofread and check. The instructor asks the students to take a serious check, and eventually put forward some suggestions for further improvement of the translation.

b) Classroom translation results display: in order to make sure that all the students in the class get a comprehensive understanding of the translation, students need to show their translation results between groups. When a group has finished the work, the instructor can interact with the students in different forms. At last, teachers should show students a reference of the translation task, to provide a comprehensive reference to students.

c) Excellent work show: select outstanding translation works from all translation groups, and commend the creator of the work, to promote the students' enthusiasm and interest in the practice of translation. Any encouragement or praise from a teacher will give students more confidence in the translation activities. As long as the members of the group are able to discuss and cooperate seriously, teachers should give appropriate encouragement and praise. If possible, some small reward mechanisms should be set up to make the translation process more complete and interesting.

\section{Empirical Research}

\subsection{Research objective}

This paper focus on the application of translation workshop in translation teaching for English majors in colleges and universities, and the cultivation of students' practical ability in translation. In this sense, the clear purpose of this study is to verify the effectiveness of translation workshops applied to the teaching of English translation in colleges and universities.

\subsection{Research object}

The objects in the study are 60 students of English education major. They come from two classes on average. One class is treated as experimental group while another treated as control group. In the study, the two classes take two different teaching methods for teaching: experimental class using translation workshop teaching method and control class using traditional teaching method.

\subsection{Research methods}

We designed a series of steps related to teaching methods to conduct effective teaching experiments.

a) Pre-test: firstly, all test materials are selected from standard textbooks; secondly, the content of the test is closely related to what the students learn in the future teaching experiment; thirdly, pre-test and post-test is ensured as consistent as possible in terms of content structure and difficulty.

b) Questionnaire investigation: the subjects will be sent questionnaires after pre-test. The purpose of the questionnaire is to understand the students' interest, attitude and opinion of translation teaching.

c) Post-test: the score standard of post-test is consistent with that of the pre-test. The post-test data collection is to analyze the students' previous translation learning performance.

d) Interview: the last step of the study is to make a brief interview with some of the subjects in the experimental class, and the main purpose is to further understand the students' attitudes, opinions and suggestions on the teaching model of the translation workshop, because these factors are likely to be 
ignored in the questionnaire for post-test research. We selected 10 students to perform the interview.

\subsection{Statistical analysis}

We obtained some data from the study, and complete the statistical analysis. The statistical result of pre-test is shown as Table 2 and Table 3.

Table 2. Mathematical statistics of pre-test score

\begin{tabular}{|c|c|c|}
\hline & Experimental class & Control class \\
\hline Effective & 30 & 30 \\
\hline Missing & 0 & 0 \\
\hline Mean & 79.53 & 79.33 \\
\hline Standard error of mean & 1.0764 & 1.098 \\
\hline Standard deviation & 5.8955 & 5.8238 \\
\hline
\end{tabular}

Table 3. Distribution of pre-test score

\begin{tabular}{|c|c|c|c|c|c|c|}
\hline & Above 90 & $80-89$ & $70-79$ & $60-69$ & Below 60 & Pass rate \\
\hline Experimental class & $3.33 \%$ & $43.33 \%$ & $50 \%$ & $3.33 \%$ & $0 \%$ & $100 \%$ \\
\hline Control class & $16.67 \%$ & $33.33 \%$ & $40 \%$ & $10 \%$ & $0 \%$ & $100 \%$ \\
\hline
\end{tabular}

We can see from the tables that there is no significant difference between the two groups.

The statistical result of post-test is shown as Table 4 and Table 5.

Table 4. Mathematical statistics of post-test score

\begin{tabular}{|c|c|c|}
\hline & Experimental class & Control class \\
\hline Effective & 30 & 30 \\
\hline Missing & 0 & 0 \\
\hline Mean & 86.00 & 82.20 \\
\hline Standard error of mean & 1.389 & 1.606 \\
\hline Standard deviation & 1.882 & 4.832 \\
\hline
\end{tabular}

Table 5. Distribution of post-test score

\begin{tabular}{|c|c|c|c|c|c|c|}
\hline & Above 90 & $80-89$ & $70-79$ & $60-69$ & Below 60 & Pass rate \\
\hline Experimental class & $26.67 \%$ & $60 \%$ & $13.33 \%$ & $0 \%$ & $0 \%$ & $100 \%$ \\
\hline Control class & $26.67 \%$ & $53.33 \%$ & $13.33 \%$ & $6.67 \%$ & $0 \%$ & $80 \%$ \\
\hline
\end{tabular}

The post-test score help to explore if there is significant change after a semester's teaching experiment between the two groups. The above tables reveals that the difference is quite obvious. In terms of grade distribution, obviously, the average grade of the experimental class after the test is relatively higher than that of the control class.

Teachers have always used the translation workshop teaching method to teach students in the experimental class, so we can concluded that the application of the translation workshop to the teaching of English translation in colleges and universities can improve the students' translation ability.

\section{Conclusion}

In our interview, most of the subjects affirm the feasibility and applicability of translation workshops applied to translation teaching in colleges and universities. They thought that this method is very practical and it can provide the most practical translation knowledge and skills for the learners.

In summary, through the study, we can know that, the translation workshop is a very practical and effective teaching method applied to the teaching of translation in colleges and universities. 
Compared with traditional teaching method, the teaching method of translation workshop not only helps to improve the learners' ability to translate, but also improves their interest in translation. In practice, teachers in colleges and universities should try to use different kinds of teaching methods and strategies to improve the quality of teaching, including translation workshop or other new teaching methods.

\section{References}

[1] Li M A, Zhong W. A Guide for Conducting Translation Workshop[J]. Chinese Translators Journal, 2010.

[2] Zeng L X, Sun X Y. A Study on Translation Workshop Teaching Model of CAT[J]. Journal of Gansu Normal Colleges, 2016.

[3] Wang Y M, Sun X Y. A Study on the Application of the Translation Workshop in Translation Teaching[J]. Journal of Gansu Normal Colleges, 2017.

[4] Ran L I. The Management of Teaching Projects in the Translation Workshop within the Purview of Cognitive Apprenticeship[J]. Journal of Xian Aeronautical University, 2016.

[5] Wang Y, Xiao W, Xue J I. An Empirical Study of the Translation Workshop in Sci-tech Translation Teaching[J]. Journal of Dongguan University of Technology, 2017.

[6] Huang Y. The Application of Workshop Model in Classroom Teaching of Translation and Interpretation[J]. Journal of Linyi University, 2011. 